\title{
ZEKE-PFI spectroscopy of 1:1 complexes of sodium with water and ammonia
}

\author{
David A. Rodham ${ }^{\text {a }}$, Geoffrey A. Blake ${ }^{\text {b }}$ \\ a Division of Chemistry and Chemical Engineering, 139-74, California Institute of Technology, Pasadena, CA 91125, USA \\ ${ }^{b}$ Division of Geological and Planetary Sciences, 170-25, California Institute of Technology, Pasadena, CA 91125, USA
}

Received 11 June 1996; in final form 7 November 1996

\begin{abstract}
ZEKE-PFI (zero kinetic energy pulsed field ionization) photoelectron spectra of the $\mathrm{Na}\left(\mathrm{H}_{2} \mathrm{O}\right), \mathrm{Na}\left(\mathrm{D}_{2} \mathrm{O}\right), \mathrm{Na}\left(\mathrm{NH}_{3}\right)$, and $\mathrm{Na}\left(\mathrm{ND}_{3}\right)$ complexes are reported. Spectra of all four complexes were obtained by single-photon ionization, and, for the $\mathrm{Na}\left(\mathrm{NH}_{3}\right)$ and $\mathrm{Na}\left(\mathrm{ND}_{3}\right)$ complexes, by two-color $\left(1+1^{\prime}\right)$ photoionization as well, with the $\tilde{\mathrm{A}}^{2} \mathrm{E}$ state serving as the intermediate resonance. Improved values for the ionization energies (IE) and intermolecular vibrational frequencies of the complexes were determined. The single-photon ZEKE-PFI spectra show transitions only between states of the same vibrational symmetry, in accord with the selection rule for allowed electronic transitions. Some of the two-color ZEKE-PFI spectra, however, show strong transitions between states of different vibrational symmetry which we attribute to vibronic coupling in the intermediate state.
\end{abstract}

\section{Introduction}

Alkali metal ions solvated by water and other polar molecules have received considerable attention [1-5] due to their importance in many chemical and biological systems, the central nervous system being a prime example. An accurate description of the manner in which the alkali ion-solvent and solvent-solvent interactions change within the solvation shells as a function of ionic radius is required to explain phenomena such as ion selectivity in membrane channels [6], but adequately detailed information is difficult to obtain from condensed phase measurements. Consequently, many researchers have studied gas phase clusters comprised of a metal ion attached to a few solvent molecules, since they form more accessible models of solution behavior. For clusters of the type $\mathrm{Na}^{+}\left(\mathrm{H}_{2} \mathrm{O}\right)_{n}$ and $\mathrm{Na}^{+}\left(\mathrm{NH}_{3}\right)_{n}$, the binding energies of the solvent molecules to the clusters have been measured as a function of $n[7,8]$, and, for $n \leqslant 6$, these data agree well with the results of numerous theoretical studies [9-11]. However, in the case of $\mathrm{Na}^{+}\left(\mathrm{NH}_{3}\right)_{n}$ clusters there is less agreement on the number of solvent molecules required to fill the first solvation shell, with estimates ranging from 4 to 6 having been obtained by various methods $[8,11,12]$.

While quantitative intermolecular potential energy surfaces (IPESs) can be obtained from high-resolution spectra of the cluster intermolecular vibrational modes, as has been demonstrated in the case of hydrogen-bonded dimers [13], the absence of such data has thus far prevented the determination of the IPESs of $\mathrm{Na}^{+}\left(\mathrm{H}_{2} \mathrm{O}\right)_{n}$ and $\mathrm{Na}^{+}\left(\mathrm{NH}_{3}\right)_{n}$ clusters. Indeed, the only measurements of intermolecular vibrational modes of such clusters were made by Hertel 
and co-workers, who determined the sodium ionmolecule stretching vibrational frequencies for the $1: 1$ complexes of $\mathrm{Na}^{+}$with water and ammonia from photoionization efficiency (PIE) spectra of the neutral dimers $[14,15]$.

Neutral clusters composed of an alkali metal atom and solvent molecules are also of interest in their own right because of their utility in the study of electron solvation [16-20]. In this context, it is interesting to note that the ionization energies (IE) of clusters with $n \leqslant 20$ determined from PIE spectra reveal that while the $\mathrm{Na}\left(\mathrm{NH}_{3}\right)_{n}$ IEs decreased monotonically with $n$, those for $\mathrm{Na}\left(\mathrm{H}_{2} \mathrm{O}\right)_{n}$ decreased until $n=4$, whereupon they reached the bulk value and remained essentially constant [21]. Misaizu et al. found the same trends in the IEs of clusters of cesium atoms with water or ammonia [22].

Theoretical studies have offered two possible explanations for the different IE behavior of sodiumwater and sodium-ammonia clusters. Using local spin density functional theory, Barnett and Landman [23] found that the $\mathrm{Na}$ atoms in $\mathrm{Na}\left(\mathrm{H}_{2} \mathrm{O}\right)_{n}$ clusters with $n \geqslant 4$ are surrounded by $\mathrm{H}_{2} \mathrm{O}$ molecules and that the $\mathrm{Na} 3$ s electron is partially removed from the atom and delocalized in a 'surface Rydberg-like state.' They claim that delocalization would not occur to the same extent in $\mathrm{Na}\left(\mathrm{NH}_{3}\right)_{n}$ clusters with $n \leqslant 30$, and that the cluster IEs will change until this size is reached. In an ab initio MO study, Hashimoto and Morokuma $[10,11]$ found that the $\mathrm{Na}$ atom is surrounded by $\mathrm{NH}_{3}$ molecules and that the $3 \mathrm{~s}$ electron is partially delocalized in large clusters, but in large $\mathrm{Na}\left(\mathrm{H}_{2} \mathrm{O}\right)_{n}$ clusters they predict the $\mathrm{Na}$ atom is attached to the surface of a water cluster with the $3 \mathrm{~s}$ electron located outside the water cluster and the IE largely unaffected by the addition of water molecules. Unfortunately, no direct structural evidence for either the neutral or ionized clusters has been obtained, and much more vibration-rotation data is needed to characterize their IPESs.

As our initial step toward a general description of alkali metal-solvent interactions, we have conducted a study of $1: 1$ complexes of sodium with water or ammonia in the gas phase using ZEKE-PFI (zero kinetic energy-pulsed field ionization) photoelectron spectroscopy. It is well documented that the IEs of neutral clusters and the rovibrational energy levels of the ionized clusters can be measured more accurately with ZEKE-PFI spectroscopy than with energy-resolved photoelectron or PIE spectroscopies [24-27]. From our ZEKE-PFI spectra we have obtained improved IEs for the $\mathrm{Na}\left(\mathrm{H}_{2} \mathrm{O}\right)$ and $\mathrm{Na}\left(\mathrm{NH}_{3}\right)$ dimers and improved sodium ion-molecule stretching vibrational frequencies for the ionized complexes. We also report here the first measurement of the intermolecular bending vibrational frequencies for the $\mathrm{Na}^{+}\left(\mathrm{NH}_{3}\right)$ and $\mathrm{Na}^{+}\left(\mathrm{ND}_{3}\right)$ complexes.

\section{Experimental}

Neutral complexes were formed and interrogated in a three-stage, differentially pumped vacuum chamber which included a 'pick-up' cluster source, a ZEKE-PFI spectrometer, and a reflectron time-offlight (TOF) mass spectrometer. The 'pick-up' $[14,15]$ source consisted of a pulsed supersonic jet which contained the water or ammonia molecules and a sodium beam that intersected the supersonic jet at right angles. The sodium atoms, after undergoing several collisions, were entrained in the jet, and a small fraction of them formed clusters. The sodium beam was produced by heating a sodium-filled stainless steel oven with a $3 \mathrm{~mm}$ diameter aperture to 630 $K$. The oven's aperture was placed approximately 5 $\mathrm{mm}$ below and $5 \mathrm{~mm}$ downstream of the orifice of the pulsed valve (General Valve Series 9, $0.8 \mathrm{~mm}$ nozzle diameter). For complexes with water, a mixture of $1 \mathrm{~atm}$ of water vapor and $1.5 \mathrm{~atm}$ of argon was expanded through the valve, while for ammonia complexes, ammonia at a pressure of 3 atm was expanded neat. After passing through a $2 \mathrm{~mm}$ diameter skimmer placed $50 \mathrm{~mm}$ away from the pulsed valve orifice, the molecular beam travelled $48 \mathrm{~cm}$ before reaching the ZEKE-PFI spectrometer's ionization region. The ZEKE-PFI spectrometer, which was fabricated from the modified ionization source of a commercial TOF mass spectrometer (R.M. Jordan Co.), consisted of two mesh grids used for extracting the electrons, a third grid that provided additional acceleration, a $\mu$-metal flight tube, and a microchannel plate detector. Ionization of the high- $n$ Rydberg states was accomplished by a pulsed electric field applied between the extraction grids $2.5 \mu$ s after the excitation laser intersected the cluster beam, with a typical magnitude of $4 \mathrm{~V} / \mathrm{cm}$ and a risetime of 80 
ns. The post-extraction acceleration grid and the $\mu$-metal tube were held at a potential of $9 \mathrm{~V}$. In the single-photon experiments, the complexes were probed with the frequency-doubled output of a dye laser (Lambda Physik FL 3002) pumped by a Nd:YAG laser (Continuum YG681). In the two-color experiments, the fundamental outputs of two FL3002 dye lasers which had bandwidths of $\approx 0.2 \mathrm{~cm}^{-1}$ were used. The wavelengths of the dye lasers were calibrated with a wavemeter (Burleigh WA-4500A) and corrected to their vacuum values. The ZEKE-PFI signal was amplified and then recorded on a digital oscilloscope (LeCroy 9400A). The ZEKE-PFI peak heights were not corrected for the variations of laser power with wavelength.

\section{Results and discussion}

Single-photon ZEKE-PFI spectra of $\mathrm{Na}\left(\mathrm{H}_{2} \mathrm{O}\right)$ and $\mathrm{Na}\left(\mathrm{D}_{2} \mathrm{O}\right)$ are presented in Fig. 1, while those for $\mathrm{Na}\left(\mathrm{NH}_{3}\right)$ and $\mathrm{Na}\left(\mathrm{ND}_{3}\right)$ are shown in Fig. 2. We associate the first and most intense peak in each spectrum with the $\Delta v=0$ transition from the neutral complex's vibronic ground state to the vibronic ground state of the cation. This transition is denoted by $0_{0}^{0+}$. Here the notation $\nu_{u^{\prime \prime}}^{v^{\prime}}$ is such that the leading number refers to the vibrational mode involved in the transition, with the subscript and superscript denoting the vibrational quantum number in the lower and upper state, respectively. Quantum numbers of cations are followed by a plus symbol. The vibronic ground states of the neutral and ionized $\mathrm{Na}\left(\mathrm{NH}_{3}\right)$ and $\mathrm{Na}\left(\mathrm{ND}_{3}\right)$ complexes have $\mathrm{A}_{1}$ symmetry in the $C_{3 v}$ point group [28], while the vibronic ground states of the neutral and ionized $\mathrm{Na}\left(\mathrm{H}_{2} \mathrm{O}\right)$ and $\mathrm{Na}\left(\mathrm{D}_{2} \mathrm{O}\right)$ complexes have $\mathrm{A}_{1}$ symmetry in the $\mathrm{C}_{2 \mathrm{v}}$ point group.

Adiabatic ionization energies of $35323 \pm 10 \mathrm{~cm}^{-1}$ for $\mathrm{Na}\left(\mathrm{H}_{2} \mathrm{O}\right), 35249 \pm 10 \mathrm{~cm}^{-1}$ for $\mathrm{Na}\left(\mathrm{D}_{2} \mathrm{O}\right), 34435$ $\pm 10 \mathrm{~cm}^{-1}$ for $\mathrm{Na}\left(\mathrm{NH}_{3}\right)$, and $34368 \pm 10 \mathrm{~cm}^{-1}$ for $\mathrm{Na}\left(\mathrm{ND}_{3}\right)$ are derived from the spectra. While ZEKEPFI spectroscopy is capable of giving more accurate IEs, the uncertainties of these values are large because of as yet unresolved rotational structure in the peaks and because no correction has been made for the lowering of the IE by the extraction field. The
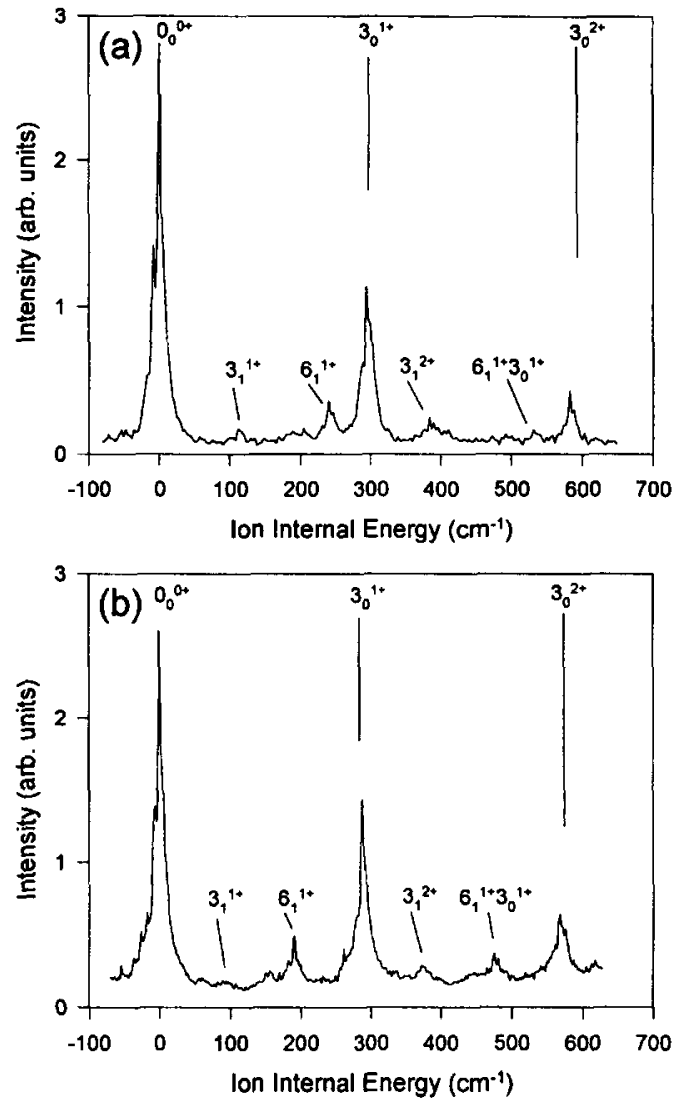

Fig. 1. Single-photon ZEKE-PFI spectra of (a) $\mathrm{Na}\left(\mathrm{H}_{2} \mathrm{O}\right)$ and (b) $\mathrm{Na}\left(\mathrm{D}_{2} \mathrm{O}\right)$.

field-induced shift of the IE is denoted by $\Delta E$ and is given in $\mathrm{cm}^{-1}$ by $\Delta E=a F^{1 / 2}$ where $F$ is the electric field in $\mathrm{V} / \mathrm{cm}$ and $a$ is a constant that generally falls between 2 and 6 [27]. However, we have not accurately determined $a$ for the complexes in this study. The adiabatic IEs for $\mathrm{Na}\left(\mathrm{H}_{2} \mathrm{O}\right)$ and $\mathrm{Na}\left(\mathrm{NH}_{3}\right)$ are, nevertheless, in excellent agreement with values obtained from PIE spectra by Schulz et al. [14] and Nitsch et al. [15] and with calculated values $[10,11,23]$, while the adiabatic IEs of the deuterated complexes are shifted $\approx 70 \mathrm{~cm}^{-1}$ to lower frequency because of the changes in their zero point vibrational energies.

We assign the other peaks in these single-photon ZEKE-PFI spectra to transitions involving the sodium ion-molecule stretching and bending vibrational modes. The $\mathrm{Na}\left(\mathrm{NH}_{3}\right)$ and $\mathrm{Na}\left(\mathrm{ND}_{3}\right)$ complexes each 


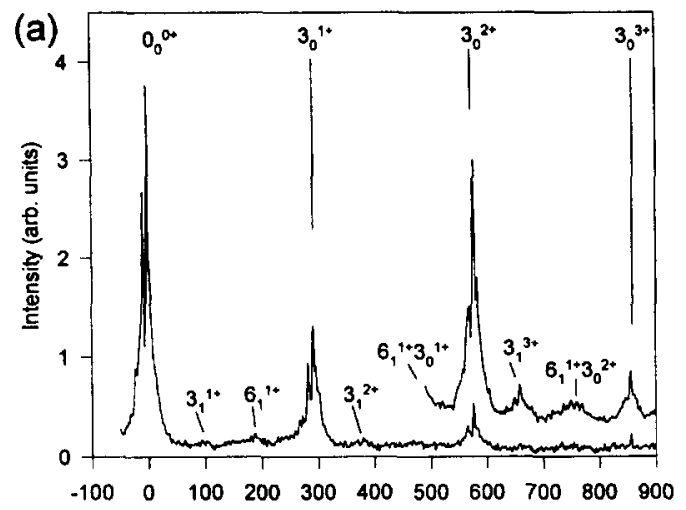

(b)

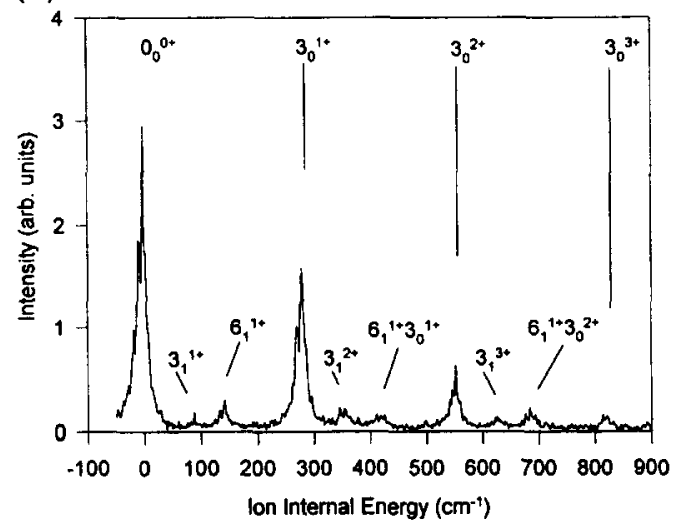

Fig. 2. Single-photon ZEKE-PFI spectra of (a) $\mathrm{Na}\left(\mathrm{NH}_{3}\right)$ and (b) $\mathrm{Na}\left(\mathrm{ND}_{3}\right)$.

have three vibrational modes of $a_{1}$ symmetry and three vibrational modes of e symmetry [29]. The sodium-ammonia stretching mode is the lowest frequency mode of $\mathrm{a}_{1}$ symmetry and is denoted by $\nu_{3}$, while the doubly degenerate sodium-ammonia bending mode is the lowest frequency mode of e symmetry and is denoted by $\nu_{6}$. The $\mathrm{Na}\left(\mathrm{H}_{2} \mathrm{O}\right)$ and $\mathrm{Na}\left(\mathrm{D}_{2} \mathrm{O}\right)$ complexes also have six vibrational modes, three of which have $a_{1}$ symmetry. The sodium-water stretching mode is the lowest frequency mode of $a_{1}$ symmetry and is again denoted by $\nu_{3}$. There are two non-degenerate sodium-water bending modes, one with $b_{1}$ symmetry and the other of $b_{2}$ symmetry, which are the lowest frequency non-totally symmetric modes in the complexes [9]. They are denoted by $\nu_{5}$ and $\nu_{6}$, but we will hereafter refer to the bending modes only as $\nu_{6}$ since, on account of spectral resolution or transition strength, only single peaks associated with the bending vibration were observed in our spectra, and no distinction between $\nu_{5}$ and $\nu_{6}$ could be made.

Following the $0_{0}^{0+}$ peak, each spectrum shows a short progression in $\nu_{3}$. The frequencies of $\nu_{3}$ are found to be $300 \pm 5 \mathrm{~cm}^{-1}$ for $\mathrm{Na}^{+}\left(\mathrm{H}_{2} \mathrm{O}\right), 296 \pm 5$ $\mathrm{cm}^{-1}$ for $\mathrm{Na}^{+}\left(\mathrm{D}_{2} \mathrm{O}\right), 305 \pm 5 \mathrm{~cm}^{-1}$ for $\mathrm{Na}^{+}\left(\mathrm{NH}_{3}\right)$, and $286 \pm 5 \mathrm{~cm}^{-1}$ for $\mathrm{Na}^{+}\left(\mathrm{ND}_{3}\right)$. The $\mathrm{Na}^{+}\left(\mathrm{H}_{2} \mathrm{O}\right)$ and $\mathrm{Na}^{+}\left(\mathrm{NH}_{3}\right)$ stretching frequencies are in excellent agreement with the values found by Schulz et al. [14] and Nitsch et al. [15], and the $\mathrm{Na}^{+}\left(\mathrm{H}_{2} \mathrm{O}\right)$ frequency is also very close to that calculated previously $[9,23]$. A summary of all the vibrational frequencies measured in this study may be found in Table 1. Unresolved rotational structure in the ZEKE-PFI peaks and the poorer signal-to-noise ratios of the higher peaks in the stretching mode progressions prevented us from measuring accurate anharmonicities. The lengths of the progressions in $\nu_{3}$ indicate that the complexes experience significant but not extremely large contractions of the sodium ion-molecule bond lengths upon ionization, also in agreement with theory. The calculated $\mathrm{Na}-\mathrm{O}$ bond lengths for the $\mathrm{Na}\left(\mathrm{H}_{2} \mathrm{O}\right)$ and $\mathrm{Na}^{+}\left(\mathrm{H}_{2} \mathrm{O}\right)$ complexes are 2.355 and $2.23 \AA$, respectively [10], while the $\mathrm{Na}\left(\mathrm{NH}_{3}\right)$ and $\mathrm{Na}^{+}\left(\mathrm{NH}_{3}\right)$ bond lengths are predicted to be 2.381 and $2.365 \AA$ [11].

The strongest peaks in the spectra in Figs. 1 and 2 are most likely produced by the ionization of neutral complexes in their vibronic ground states. There are, however, weaker peaks that may plausibly be attributed to the ionization of vibrationally excited neutral complexes. In each spectrum, the $0_{0}^{0+}$ peak and the peaks in the progression in $\nu_{3}$ are each followed by two very weak peaks at higher energy. We assign these peaks to two sets of hot bands, one

Table 1

Ionization energies (IE), intermolecular stretching vibrational frequencies $\left(\nu_{3}\right)$, and intermolecular bending vibrational frequencies $\left(\nu_{6}\right)$ determined with ZEKE-PFI spectroscopy

\begin{tabular}{lcccc}
\hline & $\mathrm{Na}\left(\mathrm{H}_{2} \mathrm{O}\right)$ & $\mathrm{Na}\left(\mathrm{D}_{2} \mathrm{O}\right)$ & $\mathrm{Na}\left(\mathrm{NH}_{3}\right)$ & $\mathrm{Na}\left(\mathrm{ND}_{3}\right)$ \\
\hline $\mathrm{IE}\left(\mathrm{cm}^{-1}\right)$ & 35323 & 35249 & 34435 & 34368 \\
$\nu_{3}^{+}\left(\mathrm{cm}^{-1}\right)$, ion & 300 & 296 & 305 & 286 \\
$\nu_{3}\left(\mathrm{~cm}^{-1}\right)$, neutral & 207 & 206 & 215 & 196 \\
$\nu_{6}^{+}\left(\mathrm{cm}^{-1}\right)$, ion & $-{ }^{\mathrm{a}}$ & $-{ }^{\mathrm{b}}$ & 468 & 340 \\
$\nu_{6}\left(\mathrm{~cm}^{-1}\right)$, neutral & $-{ }^{a}$ & $-{ }^{b}$ & 278 & 200 \\
\hline
\end{tabular}

$\nu_{6}^{+}$(ion) $-\nu_{6}($ neutral $)=240 \mathrm{~cm}^{-1}$.

$\nu_{6}^{+}($ion $)-\nu_{6}($ neutral $)=190 \mathrm{~cm}^{-1}$. 
set produced by the ionization of neutral complexes from the $\nu_{3}$ state, the other produced by complexes with $\nu_{6}$ initially populated.

The small peaks that appear $\approx 100 \mathrm{~cm}^{-1}$ above the $0_{0}^{0+}$ peaks of all four complexes probably arise from $\Delta v=0$ transitions that originate from the $v=1$ level of $\nu_{3}$. If this assignment is correct, the energy difference between the $31^{1+}$ hot band and the $0_{0}^{0+}$ peak is determined by the difference between the frequency of $\nu_{3}$ in the neutral complex and the frequency of $\nu_{3}$ in the ionized complex. The frequencies of $\nu_{3}$ in the ionized complexes, listed in Table 1 , are $\approx 300 \mathrm{~cm}^{-1}$, while in the neutral $\mathrm{Na}\left(\mathrm{H}_{2} \mathrm{O}\right)$ and $\mathrm{Na}\left(\mathrm{NH}_{3}\right)$ complexes $\nu_{3}$ has a frequency of $\approx 185 \mathrm{~cm}^{-1}$ [29]. The $3_{1}^{1+}$ transition should therefore appear $\approx 100 \mathrm{~cm}^{-1}$ higher in energy than the $0_{0}^{0+}$ transition, as observed. The shift is roughly the same for the deuterated complexes because isotopic substitution does not cause a large change in the pseudo-diatomic stretching reduced mass. A progression in $\nu_{3}$ is built upon the $3_{1}^{1+}$ false origin.

The $\mathrm{Na}\left(\mathrm{H}_{2} \mathrm{O}\right)$ spectrum exhibits a weak peak 240 $\mathrm{cm}^{-1}$ above the $0_{0}^{0+}$ peak, while the $\mathrm{Na}\left(\mathrm{NH}_{3}\right)$ spectrum shows a weak peak $190 \mathrm{~cm}^{-1}$ above its $0_{0}^{0+}$ origin. We attribute these peaks to $\Delta v=0$ transitions, but now originating from the $v=1$ level of $\nu_{6}$. Such an assignment is supported by the $\mathrm{Na}\left(\mathrm{D}_{2} \mathrm{O}\right)$ and $\mathrm{Na}\left(\mathrm{ND}_{3}\right)$ data, in which these $6_{1}^{1+}$ hot bands are located only $\approx 190$ and $\approx 140 \mathrm{~cm}^{-1}$ above the respective $0_{0}^{0+}$ peaks. This isotopic reduction of the energy difference between the $6_{1}^{1+}$ and $0_{0}^{0+}$ transitions, by almost a factor of $1 / \sqrt{ } 2$, is expected for a vibrational mode involving primarily the motion of the hydrogen atoms. In the $\mathrm{Na}\left(\mathrm{NH}_{3}\right)$ and $\mathrm{Na}\left(\mathrm{ND}_{3}\right)$ spectra, only a single peak associated with $\nu_{6}$ is expected, since $\nu_{6}$ is doubly degenerate. On the other hand, the $\mathrm{Na}\left(\mathrm{H}_{2} \mathrm{O}\right)$ and $\mathrm{Na}\left(\mathrm{D}_{2} \mathrm{O}\right)$ spectra might be expected to show one peak for each of the two non-degenerate intermolecular bending vibrational modes. The spectra in Fig. 1 hint at the existence of a second very weak peak that could be assigned as a false origin associated with another bending mode, but the signal-to-noise ratios were too poor to clarify this matter. Progressions in $\nu_{3}$ are then built upon the $6_{1}^{1+}$ false origins.

In order to measure the frequency of $\nu_{6}$ for the $\mathrm{Na}^{+}\left(\mathrm{NH}_{3}\right)$ and $\mathrm{Na}^{+}\left(\mathrm{ND}_{3}\right)$ complexes, which could not be obtained from the single-photon ZEKE-PFI spectra alone, we performed ZEKE-PFI experiments using resonant two-color $\left(1+1^{\prime}\right)$ photoionization via the $\widetilde{A}^{2} E$ state. The $\tilde{A}^{2} E$ excited electronic state of $\mathrm{Na}\left(\mathrm{NH}_{3}\right)$ has been studied theoretically by Greer et al. [28] and experimentally by Nitsch et al. [29]. A spectrum containing several vibrational bands of the $\mathrm{Na}\left(\mathrm{ND}_{3}\right) \tilde{\mathrm{A}}^{2} \mathrm{E} \leftarrow \tilde{\mathrm{X}}^{2} \mathrm{~A}$, transition, obtained by resonant two-color $\left(1+\mathrm{l}^{\prime}\right)$ photoionization spectroscopy, is shown in Fig. 3a. The peaks are assigned to the following modes: $0_{0}^{0}$ at $12250 \mathrm{~cm}^{-1}, 6_{0}^{1}$ at 12470 $\mathrm{cm}^{-1}, 3_{0}^{1}$ at $12550 \mathrm{~cm}^{-1}$, and $6_{0}^{1} 3_{0}^{1}$ at $12750 \mathrm{~cm}^{-1}$. The $6_{0}^{1}$ and $3{ }_{0}^{1}$ peaks are well resolved in this spectrum, but were not resolved in Nitsch et al.'s spectrum of the $\tilde{\mathrm{A}}^{2} \mathrm{E} \leftarrow \tilde{\mathrm{X}}^{2} \mathrm{~A}_{1}$ transition of $\mathrm{Na}\left(\mathrm{NH}_{3}\right)$ because the frequencies of $\nu_{6}$ and $\nu_{3}$ in this state
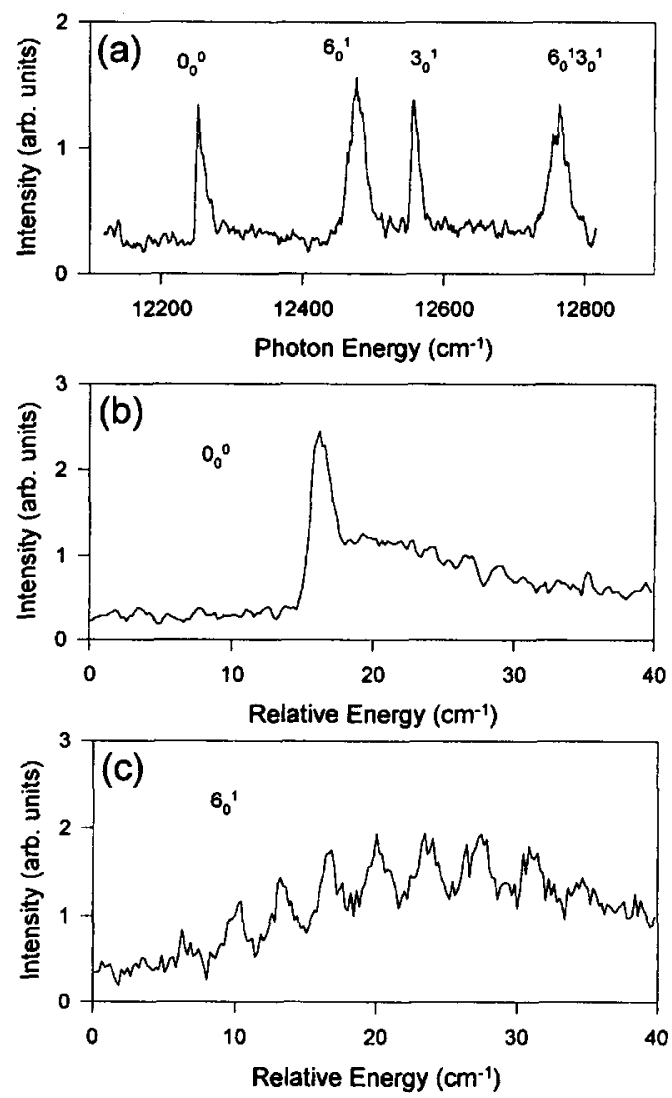

Fig. 3. Two-color $\left(1+1^{\prime}\right)$ photoionization spectra of the $\tilde{A} \leftarrow X$ transition of $\mathrm{Na}\left(\mathrm{ND}_{3}\right)$. (a) Low resolution $\left(2 \mathrm{~cm}^{-1}\right)$ spectrum. (b) High resolution $\left(0.2 \mathrm{~cm}^{-1}\right)$ scan of the $0_{0}^{0}$ band. (c) High resolution $\left(0.2 \mathrm{~cm}^{-1}\right)$ scan of the $6_{0}^{1}$ band. 
and isotopomer are almost the same. This near degeneracy led Nitsch et al. to assign peaks at higher energy to a progression in $\nu_{6}$, but the $6_{0}^{1} 3_{0}^{1}$ transition in our spectrum of $\mathrm{Na}\left(\mathrm{ND}_{3}\right)$ shows that there is a progression in $\nu_{3}$ built on the $6^{1}$ level, not a progression based solely on the $\nu_{6}$ vibrational mode.

The $6_{0}^{1}$ transition would be a forbidden transition if the Born-Oppenheimer and Condon approximations were rigorously satisfied. In such a case, the transition moment integral $M$ is given by

$M=\left\langle\psi_{\mathrm{e}}^{\prime \prime}|e r| \psi_{\mathrm{e}}^{\prime}\right\rangle\left\langle\psi_{v^{\prime \prime}}^{\prime \prime} \mid \psi_{v^{\prime}}^{\prime}\right\rangle$,

where $\psi_{\mathrm{e}}^{\prime \prime}$ and $\psi_{\mathrm{e}}^{\prime}$ are the electronic wavefunctions for the initial and final states, respectively, $\psi_{v^{\prime \prime}}^{\prime \prime}$ and $\psi_{v^{\prime}}^{\prime}$ are the corresponding vibrational wavefunctions, and $e r$ is the electric dipole moment operator. The integral containing the product of the vibrational wave functions is zero by symmetry, because e $\otimes a_{1}$ does not contain the $a_{1}$ symmetry element. However, the $6_{0}^{1}$ transition may become allowed by vibronic coupling, in which case the transition moment integral cannot be separated into electronic and vibrational components, and is given instead by

$M=\left\langle\psi_{\mathrm{e} v}^{\prime \prime}|e r| \psi_{\mathrm{ev}}^{\prime}\right\rangle$,

where $\psi_{\mathrm{e} v}^{\prime \prime}$ and $\psi_{\mathrm{e} v}^{\prime}$ are the vibronic wavefunctions for the initial and final states, respectively.

If the vibronic coupling is strong and the $\tilde{\mathrm{A}}$ state of $\mathrm{Na}\left(\mathrm{NH}_{3}\right)$ does indeed possess $\mathrm{E}$ symmetry, the $6_{0}^{1}$ transition can become allowed through the JahnTeller effect. Excitation of an e vibrational mode in an $\mathrm{E}$ electronic state produces vibronic states having $\mathrm{E}, \mathrm{A}_{1}$, and $\mathrm{A}_{2}$ symmetries. The transition from the $A_{1}$ ground state to an $E$ vibronic state is a perpendicular transition, while the transition to the $A_{1}$ vibronic state is a parallel transition and the $A_{2} \leftarrow A_{1}$ transition is forbidden. Only the $E \leftarrow A$, transition will have significant intensity, however, because it can borrow intensity from the transitions to the $\tilde{A}$ state that are allowed in the absence of vibronic coupling, which are perpendicular transitions [30].

Greer et al. predict that the second excited electronic state of $\mathrm{Na}\left(\mathrm{NH}_{3}\right)$ has $\mathrm{A}_{1}$ symmetry and lies only $2400 \mathrm{~cm}^{-1}$ above the $\tilde{A}$ state. The experimental work of Nitsch et al. suggests that there is indeed an excited electronic state only $800 \mathrm{~cm}^{-1}$ above the $\tilde{A}$ state. Since the symmetries of the lowest excited electronic states of this complex have not been deter- mined experimentally, the possibility exists that the $\tilde{\mathrm{A}}$ state has $\mathrm{A}_{1}$ symmetry and that the next highest level is of $E$ symmetry. If the $\tilde{A}$ state does have $A_{1}$ symmetry, the $6_{0}^{1}$ transition can become allowed not by the Jahn-Teller effect but by Herzberg-Teller coupling with the nearby electronic state of $\mathrm{E}$ symmetry [31]. In this case, the $0_{0}^{0}$ band would be a parallel band, and the $6_{0}^{1}$ band would be a perpendicular band because it borrows intensity from a perpendicular transition to an electronic state of $\mathrm{E}$ symmetry.

Which vibronic coupling mechanism is operative in this case must be determined from the rotational structure of the bands. Band profiles of the $0_{0}^{0}$ and $6_{0}^{1}$ transitions of $\mathrm{Na}\left(\mathrm{ND}_{3}\right)$ are shown in Fig. $3 \mathrm{~b}$ and $\mathrm{c}$. The band contours are strikingly different. The $\widetilde{\mathrm{A}} \leftarrow$ $\mathrm{X} 0_{0}^{0}$ band rises very sharply to a peak and then tails off smoothly. Such a band contour is characteristic of a parallel transition of a prolate symmetric top, with $\mathrm{P}$ branch head formation resulting from shrinkage of the $\mathrm{Na}-\mathrm{N}$ bond. The $6_{0}^{1}$ band, however, shows several sharp peaks spaced by $3.4 \mathrm{~cm}^{-1}$, which is roughly one-half of the peak spacing observed in the $\mathrm{Na}\left(\mathrm{NH}_{3}\right)$ spectrum (not shown). This spacing is very close to the rotational constant of ammonia about its $\mathrm{C}_{3}$ axis. It is also roughly an order of magnitude greater than the $B$ rotational constants of these complexes derived from the calculated structures. Such a pattern is characteristic of a perpendicular transition of a symmetric top molecule for which $A \gg B$.

If the $\tilde{\mathrm{A}} \leftarrow \mathrm{X} 0_{0}^{0}$ transition is parallel and the $6_{0}^{1}$ transition is perpendicular, the Herzberg-Teller vibronic coupling mechanism would then be responsible for the $6{ }_{0}^{1}$ transition. However, such a conclusion should not be based on unresolved rotational structure, since the structure of perpendicular bands can sometimes look like that of parallel bands. This happens because the peak spacing in a perpendicular band depends on the total vibronic angular momentum, which has an electronic component due to the degenerate electronic state and a vibrational component when the degenerate vibration is excited in that state [30]. Since the $0^{0}$ level has no vibrational angular momentum, the peak spacing in a perpendicular $0_{0}^{0}$ band will be different than in the $6_{0}^{1}$ band. A famous example of this type of behavior is the $\mathrm{C} \leftarrow \mathrm{X}$ transition of $\mathrm{CH}_{3} \mathrm{I}$, which shows such 
pseudo-parallel bands [32]. Complete rotational resolution, then, will be required to settle the issue of the electronic state ordering and the vibronic coupling mechanism operative in the $\mathrm{Na}\left(\mathrm{NH}_{3}\right)$ complex.

Two-color excitation through the vibronic levels of the $\tilde{A}$ state has been used to further characterize the IPESs of the ionized complexes, particularly through the isolation of $\nu_{6}$. Due to the $\Delta v=0$ propensity rule which generally holds in the photoionization of molecules having similar geometries in their neutral and ionized forms [33], the vibrational mode that is excited in the intermediate electronic state will usually show the strongest peak in the ZEKE-PFI spectrum. A two-color ZEKE-PFI spectrum of $\mathrm{Na}\left(\mathrm{ND}_{3}\right)$ taken via the $0^{0}$ level of the $\tilde{\mathrm{A}}$ state is shown in Fig. 4a. The strongest peak results from ionization to the cation ground state (the $0_{0}^{0+}$ transition). This $\Delta v=0$ behavior is expected, since
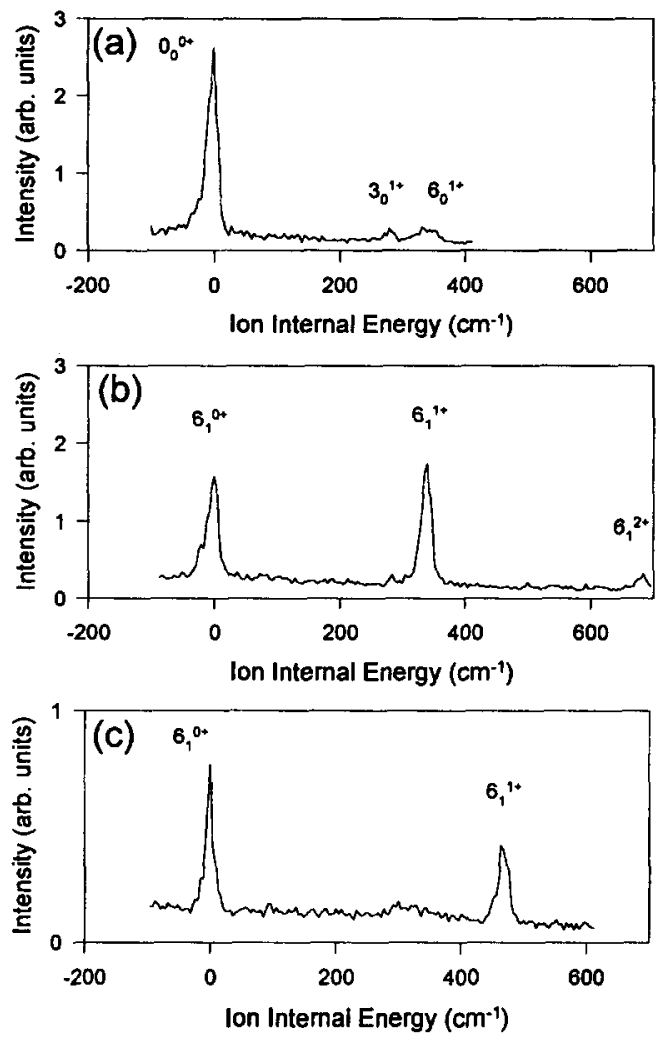

Fig. 4. Two-color ZEKE-PFI spectra of (a) $\mathrm{Na}\left(\mathrm{ND}_{3}\right)$ via the $0^{\circ}$ level of its $\tilde{A}$ state (b) $\mathrm{Na}\left(\mathrm{ND}_{3}\right)$ via the $6^{\prime}$ level of its $\tilde{\mathrm{A}}$ state (c) $\mathrm{Na}\left(\mathrm{NH}_{3}\right)$ via the $6^{\prime}$ level of its $\tilde{\mathrm{A}}$ state. the calculated geometry of the $\tilde{\mathrm{A}}$ state of the $\mathrm{Na}\left(\mathrm{NH}_{3}\right)$ complex is very close to that of the $\mathrm{Na}^{+}\left(\mathrm{NH}_{3}\right)$ complex. Two weaker peaks appear 290 and 340 $\mathrm{cm}^{-1}$ higher in energy, and are assigned to the $3_{0}^{1+}$ and $6_{0}^{1+}$ transitions, respectively. It should be noted that the $30^{1+}$ transition is much weaker than in the single-photon ZEKE-PFI spectrum, and this probably indicates that the $\mathrm{Na}-\mathrm{N}$ bond is shorter in the $\tilde{\mathrm{A}}$ state than in the ground state of the neutral complex, as Greer et al. have suggested.

Two-color ZEKE-PFI spectra taken via the $6^{1}$ level in the $\tilde{A}$ state of the $\mathrm{Na}\left(\mathrm{ND}_{3}\right)$ and $\mathrm{Na}\left(\mathrm{NH}_{3}\right)$ complexes are shown in Fig. $4 \mathrm{~b}$ and $\mathrm{c}$, respectively. The assignment of the $\mathrm{Na}\left(\mathrm{ND}_{3}\right) 6_{0}^{1+}$ transition in Fig. 4a is supported by the spectrum in Fig. 4b, which shows a strong peak for the $6_{1}^{0+}$ transition, a strong feature $340 \pm 10 \mathrm{~cm}^{-1}$ above the $6_{1}^{0+}$ peak corresponding to the $6_{1}^{1+}$ transition, and a weak peak $680 \mathrm{~cm}^{-1}$ above the $6_{1}^{0+}$ peak that we assign to the $6_{1}^{2+}$ transition. The spectrum of $\mathrm{Na}\left(\mathrm{NH}_{3}\right)$ in Fig. $4 \mathrm{c}$ was obtained by tuning the excitation laser to the low-frequency side of the spectral feature formed by the superposition of the $6_{0}^{1}$ and 31 bands in the $\mathrm{Na}\left(\mathrm{NH}_{3}\right) \tilde{\mathrm{A}} \leftarrow \tilde{\mathrm{X}}$ transition. It shows a strong $6_{1}^{0+}$ peak and a strong peak $468 \pm 10 \mathrm{~cm}^{-1}$ higher in energy, which we assign as the $6_{1}^{1+}$ transition. The intensity of the $6_{1}^{0+}$ peak is greater than that of the $6_{1}^{1+}$ peak, seemingly in violation of the $\Delta v=0$ propensity rule. This deviation from expected behavior is partly due to a loss of intensity in the ionization laser beam as the blue edge of the laser dye's tuning curve was approached. However, it is significant that the $6_{1}^{0+}$ transition appears with intensity comparable to that of the $6_{1}^{1+}$ transition.

The ratio of the frequencies of the $\nu_{6}$ vibrational modes of the $\mathrm{Na}^{+}\left(\mathrm{ND}_{3}\right)$ and $\mathrm{Na}^{+}\left(\mathrm{NH}_{3}\right)$ complexes is 0.726 , which is approximately what one would expect for this bending mode. The $\mathrm{Na}^{+}\left(\mathrm{NH}_{3}\right)$ bending frequency is also reasonably close to the bending frequencies calculated for the $\mathrm{Na}^{+}\left(\mathrm{H}_{2} \mathrm{O}\right)$ complex [9]. The increased 'stiffness' in the bending coordinate relative to the stretching coordinate results from the directionality of the ion-dipole force which is the main contributor to the bonding in this complex [29].

Combining these results with the changes in the $\nu_{6}$ modes derived from the hot bands observed in the single-photon ZEKE-PFI spectra, frequencies for $\nu_{6}$ 

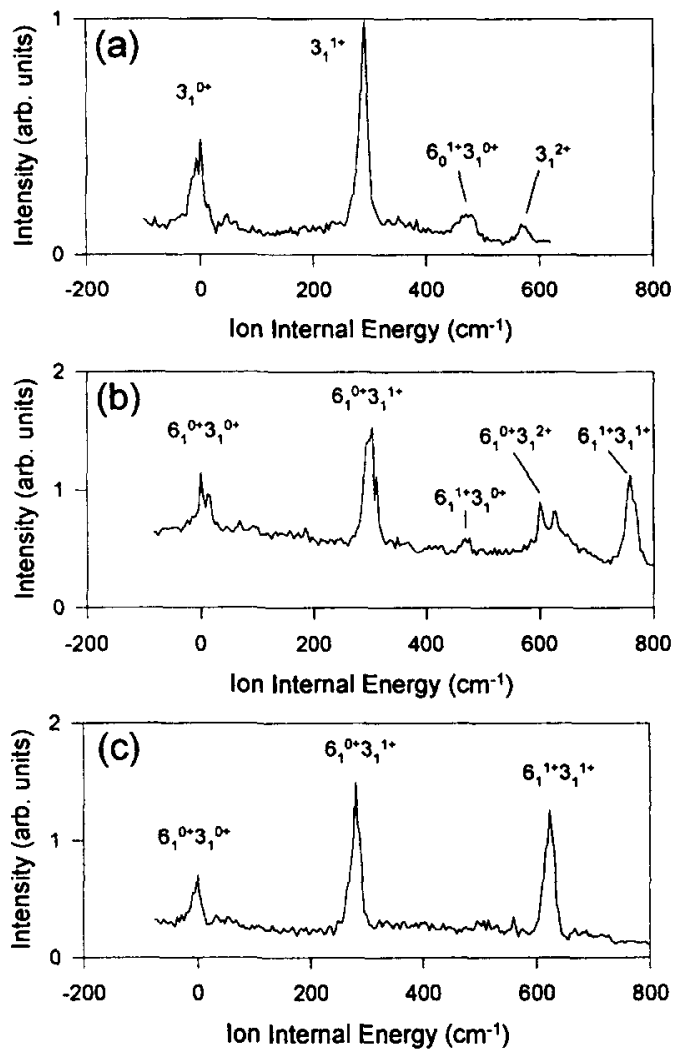

Fig. 5. Two-color ZEKE-PFI spectra of (a) $\mathrm{Na}\left(\mathrm{NH}_{3}\right)$ via the $3^{1}$ level of its $\tilde{\mathrm{A}}$ state (b) $\mathrm{Na}\left(\mathrm{NH}_{3}\right)$ via the $6^{1} 3^{1}$ level of its $\tilde{\mathrm{A}}$ state (c) $\mathrm{Na}\left(\mathrm{ND}_{3}\right)$ via the $6^{1} 3^{1}$ level of its $\tilde{\mathrm{A}}$ state.

in the neutral $\mathrm{Na}\left(\mathrm{NH}_{3}\right)$ and $\mathrm{Na}\left(\mathrm{ND}_{3}\right)$ complexes are found to be $278 \pm 20$ and $200 \pm 20 \mathrm{~cm}^{-1}$, respectively. It is somewhat surprising that the bending frequency for the neutral $\mathrm{Na}\left(\mathrm{NH}_{3}\right)$ complex is higher than that for the stretching mode, since the calculations that have been done on similar species to date have found that the stretching frequencies are higher [19]. The measurement of the vibrational frequencies of other alkali metal-molecule complexes should shed considerable light on the nature of the bonding interactions in these neutral complexes.

The assigned frequency of $\nu_{6}$ for the $\mathrm{Na}^{+}\left(\mathrm{NH}_{3}\right)$ complex is supported by the spectrum presented in Fig. 5a, taken via the $3^{1}$ level of the $\tilde{A}$ state. The strongest peak in the spectrum is assigned to the $31^{1+}$ transition, and weak peaks that we assign to the $3_{1}^{0+}$, $6_{0}^{1+} 3_{1}^{0+}$, and $3_{1}^{2+}$ transitions are evident. The $6_{0}^{1+} 3_{1}^{0+}$ peak is $470 \mathrm{~cm}^{-1}$ above the $3_{1}^{0+}$ peak.
ZEKE-PFI spectra of $\mathrm{Na}\left(\mathrm{NH}_{3}\right)$ and $\mathrm{Na}\left(\mathrm{ND}_{3}\right)$ taken via the $6^{1} 3^{1}$ level of the $\tilde{A}$ state are shown in Fig. $5 b$ and c. The $\mathrm{Na}\left(\mathrm{NH}_{3}\right)$ spectrum shows a $6_{1}^{0+} 3_{1}^{0+}$ peak, a $6_{1}^{0+} 3_{1}^{1+}$ peak, a $6_{1}^{0+} 3_{1}^{2+}$ peak, and a peak $770 \mathrm{~cm}^{-1}$ above the $6_{1}^{0+} 3_{1}^{0+}$ peak that we assign to the $6_{1}^{1+} 3_{1}^{1+}$ transition. The $6_{1}^{1+} 3_{1}^{0+}$ transition appears with very little intensity. The $\mathrm{Na}\left(\mathrm{ND}_{3}\right)$ spectrum shows a peak for the $6_{1}^{0+} 3_{1}^{0+}$ transition, a peak for the $6_{1}^{0+} 3_{1}^{1+}$ transition $280 \mathrm{~cm}^{-1}$ above it, and a third peak $624 \mathrm{~cm}^{-1}$ above $6_{1}^{0+} 3_{1}^{0+}$ peak that corresponds to the $6_{1}^{1+} 3_{1}^{1+}$ transition. These spectra confirm our assignments of the intermediate states.

The most startling aspect of the ZEKE-PFI spectra taken via the $6^{1} 3^{1}$ level is the violation of the $\Delta v=0$ propensity rule by strong transitions to ion vibrational states of different symmetry. The spectra show the expected $\Delta v=0$ transition to the $6^{1+} 3^{1+}$ level which has e symmetry, but also strong transitions to the origin and the $3^{1+}$ level, which have $a_{1}$ symmetry. Interestingly, the peak for the transition to the $6^{1+}$ level is weak or non-existent. Similar behavior is observed in the spectra taken via the $6^{\prime}$ level, shown in Fig. $4 \mathrm{~b}$ and $\mathrm{c}$, which show the $\Delta v=0$ peaks for the transition to the $6^{1+}$ level as well as strong transitions to the ion ground states. In contrast, the ZEKE-PFI spectra shown in Figs. 4 and 5a, taken via states of $a_{1}$ vibrational symmetry that possess no excitation of $\nu_{6}$, show only very weak transitions to states of e vibrational symmetry. Thus, the selection rule for allowed electronic transitions which forbids interactions between states of different vibrational symmetry (see Eq. (1)) is most closely followed in the single-photon ZEKE-PFI spectra, which show only transitions between states having the same vibrational symmetry.

We attribute the transitions between states of different vibrational symmetry to strong vibronic coupling in the $\tilde{\mathrm{A}}$ state, which our spectra of the $\tilde{\mathrm{A}}$ state have shown to exist. We note that vibronic coupling in the intermediate electronic state has been found to be responsible for transitions between states of different vibrational symmetry in two-color ZEKE-PFI spectra of other molecules [34,35]. It is possible that the transitions could result from vibronic coupling in the cation, but this would require either the existence of low-lying excited electronic states in the cation or degeneracy of the ground electronic state of the cation. To our knowledge, 
neither condition is satisfied in the $\mathrm{Na}^{+}\left(\mathrm{NH}_{3}\right)$ complex. Further understanding of vibronic coupling in this complex, as well as the structural parameters of complexes of sodium ions with ammonia, water and other molecules, can be obtained from rotationally resolved two-color ZEKE-PFI spectra which are currently being taken in our laboratory.

\section{Acknowledgements}

The authors gratefully acknowledge support from NASA (grants NAGW-2813 and -1955) and the National Science Foundation (CHE-9415488) during the course of this work, as well as initial instrumentation funding provided by the David and Lucille Packard Foundation.

\section{References}

[1] W. Rudolph, M.H. Brooker and C.C. Pye, J. Phys. Chem. 99 (1995) 3793.

[2] J.C. Polanyi and J. Wang, J. Phys. Chem. 99 (1995) 13691.

[3] E.D. Glendening, J. Am. Chem. Soc. 118 (1996) 2473.

[4] J.E. Combariza and N.R. Kestner, J. Phys. Chem. 99 (1995) 2717.

[5] F.F. Abraham, M.R. Mruzik and G.M. Pound, Faraday Discuss. Chem. Soc. 61 (1976) 34.

[6] M.D. Toney, E. Hohenester, S.W. Cowan and J.N. Jansonius, Science 261 (1993) 756.

[7] I. Dzidic and P. Kebarle, J. Phys. Chem. 74 (1970) 1466.

[8] A.W. Castleman, Jr., P.M. Holland, D.M. Lindsay and K.I. Peterson, J. Am. Chem. Soc. 100 (1978) 6039.

[9] C.W. Bauschlicher, Jr., S.R. Langhoff, H. Partridge, J.E. Rice and A. Komomicki, J. Chem. Phys. 95 (1991) 5142.

[10] K. Hashimoto and K. Morokuma, J. Am. Chem. Soc. 116 (1994) 11436.

[11] K. Hashimoto and K. Morokuma, J. Am. Chem. Soc. 117 (1995) 4151.
[12] T.J. Selegue and J.M. Lisy, J. Phys. Chem. 96 (1992) 4143.

[13] R.J. Saykally and G.A. Blake, Science 259 (1993) 1570.

[14] C.P. Schulz, R. Haugstätter, H.U. Tittes and I.V. Hertel, Phys. Rev. Lett. 57 (1986) 1703.

[15] C. Nitsch, C.P. Schulz, A. Gerber, W. Zimmermann-Edling and I.V. Hertel, Z. Phys. D 22 (1992) 651.

[16] L. Manceron, A. Loutellier and J.P Perchard, Chem. Phys. 92 (1985) 75.

[17] P.F. Meier, R.H. Hauge and J.L. Margrave, J. Am. Chem. Soc. 100 (1978) 2108.

[18] L.A. Curtiss and J.A. Pople, J. Chem. Phys. 82 (1985) 4230.

[19] J. Bentley and I. Carmichael, J. Phys. Chem. 85 (1981) 3821.

[20] M. Trenary, H.F. Schaefer III and P. Kollman, J. Chem. Phys. 68 (1978) 4047.

[21] I.V. Hertel, C. Hüglin, C. Nitsch and C.P. Schulz, Phys. Rev. Lett. 67 (1991) 1767.

[22] F. Misaizu, K. Tsukamoto, M. Sanekata and K. Fuke, Chem. Phys. Lett. 188 (1992) 241.

[23] R.N. Bamett and U. Landman, Phys. Rev. Lett. 70 (1993) 1775.

[24] K. Müller-Dethlefs, M. Sander and E.W. Schlag, Z. Naturforsch. A 39 (1984) 1089.

[25] G. Reiser, W. Habenicht, K. Müller-Dethlefs and E.W. Schlag, Chem. Phys. Lett. 152 (1988) 119.

[26] K. Müller-Dethlefs and E.W. Schlag, Ann. Rev. Phys. Chem. 42 (1991) 109.

[27] R. Lindner, H.J. Dietrich and K. Müller-Dethlefs, Chem. Phys. Lett. 228 (1994) 417.

[28] J.C. Greer, C. Hüglin, I.V. Hertel and R. Ahlrichs, Z. Phys. D 30 (1994) 69.

[29] C. Nitsch, C. Hüglin, I.V. Hertel and C.P. Schulz, J. Chem. Phys. 101 (1994) 6559.

[30] G. Herzberg, Molecular spectra and molecular structure, Vol. 3 (Van Nostrand, Princeton, NJ, 1966).

[31] G. Herzberg and E. Teller, Z. Phys. Chem. 21 (1933) 410.

[32] R.S. Mulliken and E. Teller, Phys. Rev. 61 (1942) 283.

[33] X. Song, C.W. Wilkerson, J. Lucia, S. Pauls and J.P. Reilly, Chem. Phys. Lett. 174 (1990) 377.

[34] G. Reiser, D. Rieger, T.G. Wright, K. Müller-Dethlefs and E.W. Schlag, J. Phys. Chem. 97 (1993) 4335.

[35] M.C.R. Cockett, H. Ozeki, K. Okuyama and K. Kimura, J. Chem. Phys. 98 (1993) 7763. 